\title{
Pour Marie-Thérèse Weber
}

\section{Françoise Morvant}

\section{OpenEdition}

\section{Journals}

Édition électronique

URL : http://journals.openedition.org/esp/1365

DOI : 10.4000/esp. 1365

ISSN : 2532-0319

\section{Éditeur}

Centre d'Information sur l'Éducation Bilingue et Plurilingue

\section{Édition imprimée}

Date de publication : 1 décembre 2017

Pagination : 7-8

ISSN : 1127-266X

\section{Référence électronique}

Françoise Morvant, «Pour Marie-Thérèse Weber », Éducation et sociétés plurilingues [En ligne], 43 |

2017, mis en ligne le 01 février 2019, consulté le 24 septembre 2020. URL : http://

journals.openedition.org/esp/1365; DOI : https://doi.org/10.4000/esp.1365 


\section{POUR MARIE-THÉRÈSE WEBER}

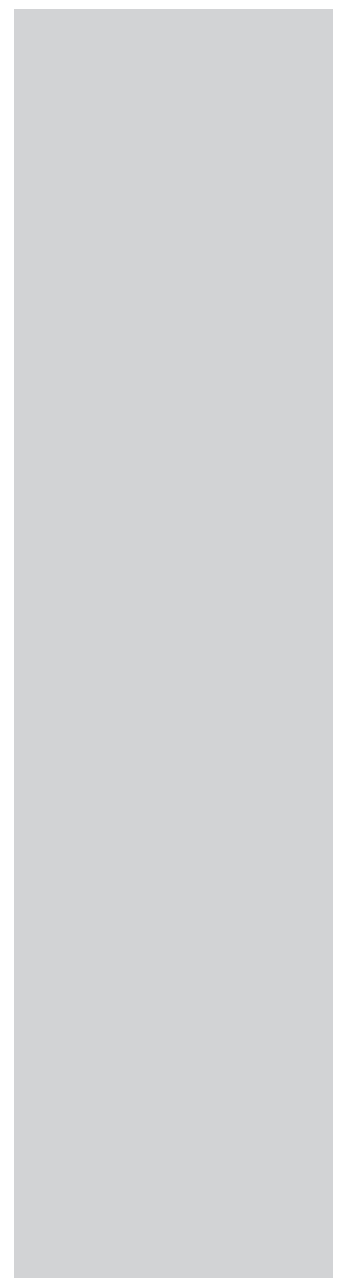

Françoise MORVANT

$\mathrm{M}$ arie-Thérèse Weber est née le 2 juin 1935 à St-Aubin, une commune à laquelle elle restera attachée toute sa vie et où elle s'est fait de nombreux amis.

D'origine bernoise par son père et valaisanne par sa mère, Marie-Thérèse en a hérité un caractère bien trempé. Exigeante avec elle-même comme avec les autres, elle s'est toujours investie à fond dans tout ce qu'elle a entrepris. Tout au long de sa vie, elle a effectué de longues études principalement en histoire, en littérature, en psychologie et en pédagogie. Ses travaux et ses recherches ont été couronnés par une licence, suivie de deux doctorats, par un ouvrage consacré au pédagogue Léon Barbey et par de nombreuses publications notamment dans le Dictionnaire historique de la Suisse.

Parallèlement, elle s'est consacrée à l'enseignement, à Bex, à Aigle, Châtel St-Denis et Bulle ainsi qu'à Fribourg, au Collège Sainte-Croix, à l'École normale et à l'ECDD. Car la pédagogie et la diffusion du savoir ont toujours été des thèmes de prédilection auxquels elle a consacré toute sa vie.

Très attachée à la connaissance des langues, Marie-Thérèse s'exprimait également avec aisance en allemand, en anglais et en italien. Elle a aussi fait de nombreuses recherches sur la question du bilinguisme et des enfants migrants, un sujet qui lui a toujours tenu à coeur. Mais les enfants et les adolescents n'ont pas été pour elle qu'un thème de recherche théorique. Marie-Thérèse a toujours été près des jeunes, non seulement de ses élèves, qu'elle avait toujours plaisir à rencontrer, mais aussi de tous ceux à qui, pendant ses moments de liberté, elle a accordé du temps et de l'attention pour les stimuler, leur transmettre ses connaissances et les aider à progresser dans leurs études.

NOTE:

La bibliographie de Marie-Thérèse Weber sera disponible sur esp.revues.org 
Pour Marie-Thérèse Weber F. MORVANT
Tout cela, Marie-Thérèse ne vous l'aurait probablement jamais dit, car, tout au long de sa vie, elle a fait preuve d'une grande retenue et d'une profonde modestie. Très croyante et fidèle pratiquante, elle a toujours été très respectueuse des autres.

Â l'occasion, elle pratiquait l'humour, mais elle restait, là aussi, fidèle à elle-même, c'est-à-dire mesurée.

Mais à côté de l'étude et des livres, Marie-Thérèse a eu d'autres passions: les voyages dans de nombreux pays d'Europe et aux États-Unis, les musées et les cathédrales, la musique classique, les vacances en Valais pour y faire de longues promenades et, bien sûr, des escapades à St-Aubin, en compagnie de sa soeur cadette, Anne-Marie, dont elle s'est occupée depuis toute petite, car toutes deux étaient encore très jeunes lorsque leur père est décédé.

Le bonheur et le bien-être de sa sœur, pour qui elle avait une immense affection, ont été une préoccupation constante pour Marie-Thérèse. C'est à fin janvier 2015 que Marie-Thérèse, qui était atteinte dans sa santé, est entrée à la Résidence des Chênes, à Fribourg. Sa sœur l'a rejointe un mois plus tard.

$\mathrm{Au}$ cours de son séjour à la Résidence, Marie-Thérèse a dû subir diverses opérations auxquelles elle a fait face avec un courage et une volonté exemplaires. Mais en dépit de son état de santé, elle a pu ou su partager d'agréables moments, en compagnie de sa sœur, des amis qui venaient leur rendre visite, ainsi que du personnel de la Résidence, qui a toujours fait preuve de chaleur et d'humanité.

Marie-Thérèse s'en est allée au soir du 8 juin. Elle venait d'avoir 82 ans.

Merci Marie-Thérèse pour tout ce que tu nous as appris.

Merci pour tout ce que tu nous a donné.

Merci pour tout ce que tu nous as dit. Parfois du bout des lèvres. Et que nous avons accueilli du fond du cœeur. 